\title{
Thermophysical Characterization of Typha's Concrete for Its Integration into Construction
}

\author{
Ababacar Sadikh Diaw ${ }^{1 *}$, Harouna Mamadou Bal'1, Oumar Diallo', \\ Mamadou Babacar Ndiaye ${ }^{1}$, Mamadou Wade ${ }^{2}$, Salif Gaye ${ }^{1}$ \\ ${ }^{1}$ Laboratory of Materials and Energetics (LME), University Institute of Technology (IUT), Thies, Senegal \\ ${ }^{2}$ Laboratory of Sciences and Technology of Water and Environment (LaSTEE), Polytechnic School of Thies, Thies, Senegal \\ Email: ^ababacars.diaw@univ-thies.sn
}

How to cite this paper: Diaw, A.S., Bal, H.M., Diallo, O., Ndiaye, M.B., Wade, M. and Gaye, S. (2021) Thermophysical Characterization of Typha's Concrete for Its Integration into Construction. Journal of Building Construction and Planning Research, 9, 56-65.

https://doi.org/10.4236/jbcpr.2021.91005

Received: October 16, 2020

Accepted: March 23, 2021

Published: March 26, 2021

Copyright $\odot 2021$ by author(s) and Scientific Research Publishing Inc. This work is licensed under the Creative Commons Attribution International License (CC BY 4.0).

http://creativecommons.org/licenses/by/4.0/

\begin{abstract}
Energy consumption in the building sector is constantly increasing and represents more than $44 \%$ in the residential and tertiary sectors in many countries [1]. Thus, the building represents a real possibility of energy saving and is the subject of several studies particularly in actual context of experimentation with materials based on plant fibers (hemp, flax, millet wastage, etc.). These biobased materials such as typha have shown real interest in the buildings construction due to their light and porous nature. It's in this context that we were interested in typha australis mixed with classic aggregates (cement, sand, gravel 3/8) to make typha's concrete. On this concrete, we carried out experimental measurements in order to better understand its contributions in the building. The interesting results obtained show that typha australis, which is an invasive and harmful grass, can be valued and integrated among local building materials in the form of typha's concrete in order to improve the energy efficiency of buildings.
\end{abstract}

\section{Keywords}

Typha Australis, Bio-Based Materials, Thermal Conductivity, Thermal Diffusivity, Energy Efficiency, Asymmetric Hot Plane

\section{Introduction}

Energy is essential for achieving Sustainable Development Goal 7 [2] which includes the need to "guarantee access for all to reliable, sustainable, modern and low-cost energy services". On the basis of this situation, several studies are carried out in order to increase the use of renewable energies and to improve energy efficiency. The building sector, being very energy-consuming ( $44 \%$ of final 
energy consumption, $40 \%$ of greenhouse gas emissions and $40 \%$ of waste produced across the planet) [1], concentrates several resilience programs including the use of renewable energies to make buildings self-sufficient and the recovery of local materials in the building [3]. Several building components can be used in particular the envelope which sometimes is made of materials sensitive to thermal exchanges. This building structure is very often constructed with conventional materials which are not necessarily favorable to the climatic conditions of the site. Therefore, the valuation of local materials, capable of regulating the thermal loads of the building [4], limits the propagation of acoustic waves and keeping the interior of buildings cool becomes imperative to ensure decent housing for the population. In addition to the advantages mentioned above, the development of local materials contributes to the valuation of resources initially considered as harmful such as Typha and offers the local population a production chain capable of generating goods and services [5]. Thus, typha australis, which is a wild herb occupying an area of around 60,000 ha with a proliferation rate of between $10 \%$ and $15 \%$ per year [3], is currently the subject of several studies for its valuation in as fuel or construction material. Previous research work on typha [6] [7] [8] has thus shown its importance in the construction sector as an insulating material capable of playing the function of filling [9]. These studies made it possible to carry out mechanical characterization tests on certain typha mortars and concretes. Using a hydraulic press, we carried out series of measurements of the mechanical compressive strength which vary between $1.83 \mathrm{MPa}$ to $13.9 \mathrm{MPa}$ for the mortar and 1.11 MPa to $11.69 \mathrm{MPa}$ for concrete [7] [9]. The results of the mechanical characterization obtained as part of our work show the relevance of using typha concrete as a slab brick at the level of the slab since they play a filling role in the construction and not a structure. In addition, the typha is a nuisance for many areas. Suddenly, its valuation will help transform a nuisance into an opportunity.

In this sense, we have studied this work on the thermophysical characteristics of typha's concrete using the hot plane asymmetry method [10] [11]. The determination of these properties will make possibility to conclude on the relevance of using typha's concrete to reduce the energy consumption of buildings.

\section{Sample and Method of Thermophysical Characterization of Typha's Concrete}

The samples used for the thermal characterization are parallelepipedal blocks with square lateral faces of $10 \mathrm{~cm}$ side (Figure 1). In this asymmetric hot plane type method, the thickness of the samples can be set at $2.5 \mathrm{~cm}$ to meet the boundary conditions of the semi-infinite area. The measurements of the properties were made at different water contents in order to simulate the building's responses to real climatic conditions.

The first step is to store the samples immediately after they have been made (unmolded) in plastic bags to avoid any loss of moisture. Bagging is not only for 
keeping the moisture in the materials but also facilitates its homogeneous distribution of it in the materials. The plastics conservation system will be maintained until the end of the measures in order to avoid mass transfers. Figure 2 presents the experimental setup.

This method known as the asymmetric hot plane type is used for the thermophysical characterization of solid materials and is very suitable for measuring the thermophysical properties of construction materials (earth-based materials, concrete, wood, plastics, etc.). The relevance of its use in such cases is justified by the fact that it's difficult to find two identical samples in their composition and in their form in construction. Therefore, an asymmetric assembly whose sample to be characterized is between two insulators of known thermal properties [12], can be retained to perform the thermal characterization of materials based on typha. The system consists of a heating element of low thickness (0.005 $\mathrm{mm})$ and its surface equivalent to the sample face $(100 \times 100 \mathrm{sqmm})$. The heating element is equipped with two wires which have small diameter $(\leq 0.05 \mathrm{~mm})$ which are glued to the side in contact with the polyurethane: they constitute the

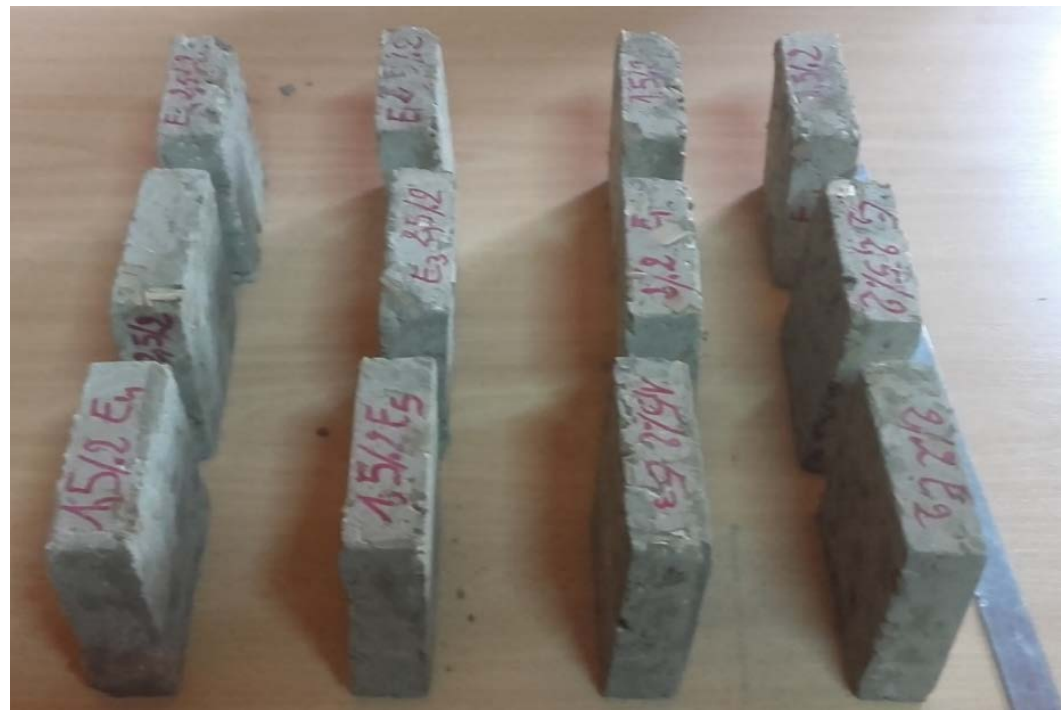

Figure 1. Samples with variable content of typha.

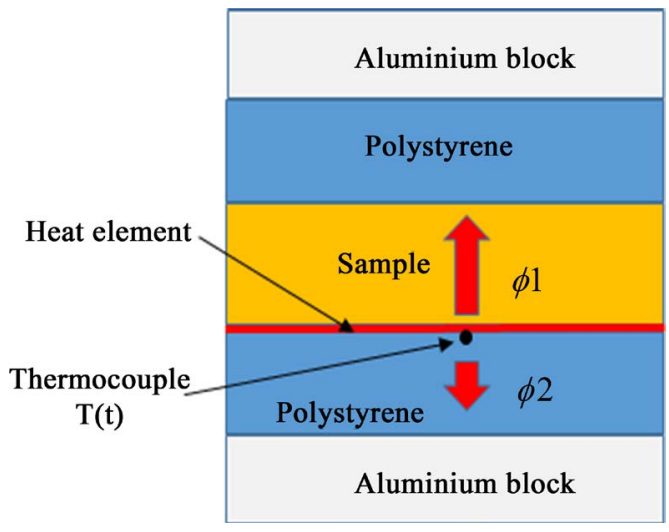

Figure 2. Experimental setup. 
thermocouple responsible for detecting the temperature change in the center of the sample. Another block of polyurethane placed above the sample allows the latter to be confined with the heating film to which a flow step will be applied as part of the measurements. The whole is sandwiched between two isothermal aluminum blocks $4 \mathrm{~cm}$ thick.

These aluminum blocks keep the temperature constant between them block and the polyurethane insulation. A clamping device allows the pressure to be controlled and kept the superimposed layers to be stable. This characterization method is quickly and easily implemented because it is in a transient state.

It measures the thermal effusivity and thermal conductivity of materials in transient conditions. From an initial thermal equilibrium situation, a step of heat flow is applied to the heating element. The thermocouple placed in the center of the heating element makes it possible to record the temperature rise $T_{0}$ at the center of the sample over time. The recording takes place over a time step of 0.1 $\mathrm{s}$ for about 20 minutes. The asymmetry assembly makes it possible to reduce the contact resistance insofar as the thermocouple, being in contact with a deformable space (polyurethane), is partially embedded in the latter: which generates a lower contact resistance.

Considering that the transverse dimensions of the heating resistor are large compared to the thickness of the sample, we can consider that the transfer is $1 \mathrm{D}$ at the center of the sample and apply the quadrupole formalism to the model shown in Figure 2:

$$
\left[\begin{array}{c}
\theta_{0} \\
\Phi_{01}
\end{array}\right]=\left[\begin{array}{cc}
1 & 0 \\
m c p & 1
\end{array}\right]\left[\begin{array}{cc}
1 & R_{c} \\
0 & 1
\end{array}\right]\left[\begin{array}{cc}
A_{e} & B_{e} \\
C_{e} & D_{e}
\end{array}\right]\left[\begin{array}{cc}
A_{i} & B_{i} \\
C_{i} & D_{i}
\end{array}\right]\left[\begin{array}{c}
0 \\
\Phi_{3}
\end{array}\right]
$$

By posing:

$$
\left[\begin{array}{ll}
A & B \\
C & D
\end{array}\right]=\left[\begin{array}{cc}
1 & 0 \\
m c p & 1
\end{array}\right]\left[\begin{array}{cc}
1 & R_{c} \\
0 & 1
\end{array}\right]\left[\begin{array}{cc}
A_{e} & B_{e} \\
C_{e} & D_{e}
\end{array}\right]\left[\begin{array}{cc}
A_{i} & B_{i} \\
C_{i} & D_{i}
\end{array}\right]
$$

one have:

$$
\left[\begin{array}{c}
\theta_{0} \\
\Phi_{01}
\end{array}\right]=\left[\begin{array}{ll}
A & B \\
C & D
\end{array}\right]\left[\begin{array}{c}
0 \\
\Phi_{3}
\end{array}\right]
$$

with:

$$
\begin{gathered}
{\left[\begin{array}{ll}
A_{e} & B_{e} \\
C_{e} & D_{e}
\end{array}\right]=\left[\begin{array}{cc}
\operatorname{ch}(q e) & \frac{\operatorname{sh}(q e)}{\lambda S q} \\
\lambda \operatorname{Sqsh}(q e) & \operatorname{ch}(q e)
\end{array}\right] \text { with } q=\sqrt{\frac{P}{a}}} \\
{\left[\begin{array}{cc}
A_{i} & B_{i} \\
C_{i} & D_{i}
\end{array}\right]=\left[\begin{array}{cc}
\operatorname{ch}\left(q_{i} e_{i}\right) & \frac{\operatorname{sh}\left(q_{i} e_{i}\right)}{\lambda_{i} S q_{i}} \\
\lambda_{i} S q_{i} \operatorname{sh}\left(q_{i} e_{i}\right) & \operatorname{ch}\left(q_{i} e_{i}\right)
\end{array}\right] \text { avec } q_{i}=\sqrt{\frac{P}{a_{i}}}}
\end{gathered}
$$

The temperatures $\theta_{0}$ and $\theta_{1}$ are obtained in the Laplace space. The reverse Laplace transformation allowing the determination of $T_{0}$ and $T_{1}$ values is done numerically by using the Stehfest algorithms [13]. The asymmetric hot-plane method makes possible the estimation thermal diffusivity and thermal conduc- 
tivity as long as the fundamental assumption of $1 \mathrm{D}$ transfer is verified [14]. The temperature only becomes sensitive to the thermal conductivity of the material from the time $t_{1}$ when the hypothesis of the semi-infinite space is no longer valid.

This time $t_{1}$ corresponds to approximately $400 \mathrm{~s}$ for the above experiment. Furthermore, the heat exchanges on the lateral side impose a convective 3D transfer, including in the center from a certain time $t_{2}$. If the time $t_{1}$ is greater than the time $t_{2}$, it will be impossible to estimate the thermal conductivity of the sample because the heat transfer including at the center will be $3 \mathrm{D}$ before the temperature becomes sensitive to the conductivity. Probe inertia and contact resistance don't influence the temperature at long times.

Parameter measurement can be performed as soon as the residue curve is centered at zero. This condition is fulfilled when the theoretically calculated temperature curve coincides with the experimental temperature curve (see Figure 3 \& Figure 4 ).

The characterization is made on two types of formulation (concrete 1 and concrete 2) which differ by the binder content. For each type of formulation, a variation in steps of $0.5 \%$ by mass of the content of typha australis allows the impact of this herb on the thermal conductivity and thermal effusivity of cement-based materials to be seen.

The formulations are summarized in the following Table 1.

\section{Results and Discussion}

For each formulation, it was possible to measure the thermal conductivity as well as the reference effusivity of the corresponding material. The thermophysical properties of concrete 1 with less cement are: $\lambda=1.079 \mathrm{~W} /(\mathrm{m} \cdot \mathrm{K}), a=5.88 \times 10^{-7}$ $\mathrm{m}^{2} \cdot \mathrm{s}^{-1}$ et $\rho \mathrm{c}=1.834 \times 10^{6} \mathrm{~J} \cdot \mathrm{m}^{-3} \cdot \mathrm{K}^{-1}$. With an addition of $0.5 \%$ by mass of typha, a

(K)

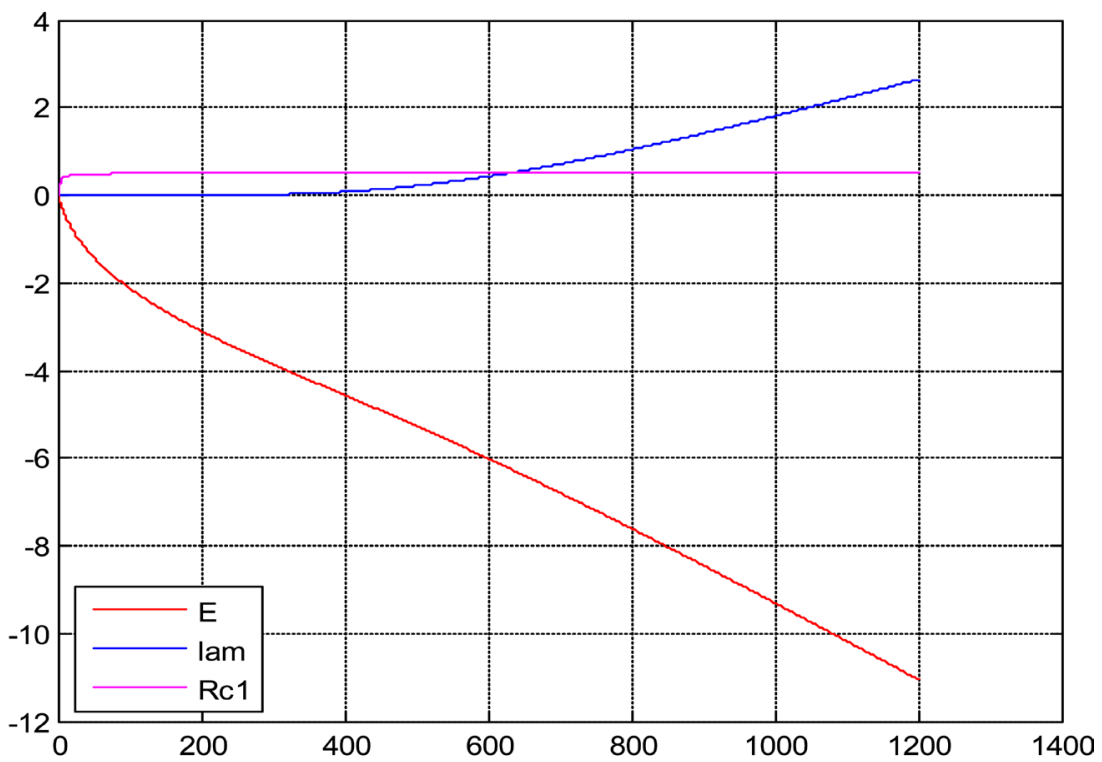

Figure 3. Sensitivity of the parameters. 


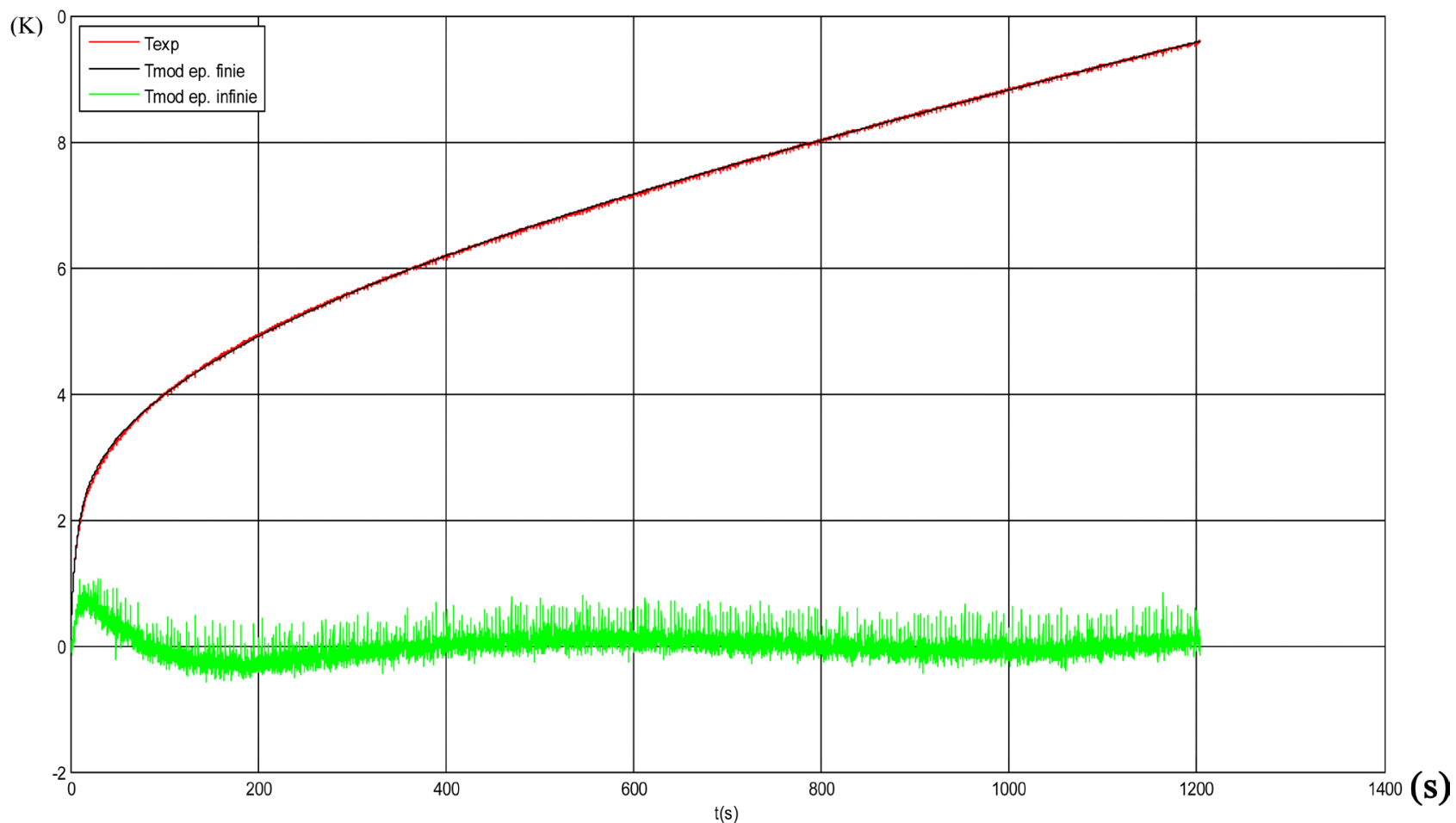

Figure 4. Residue curve.

Table 1. Formulation of the two types of concrete.

\begin{tabular}{|c|c|c|c|c|c|c|c|}
\hline \multirow{2}{*}{ Concrete } & \multirow{2}{*}{ Composition } & \multicolumn{6}{|c|}{ Mass pourcentage of Typha (\%) } \\
\hline & & 0 & 0.5 & 1 & 1.5 & 2 & 2.5 \\
\hline \multirow{4}{*}{$\begin{array}{c}\text { Concrete } \\
1\end{array}$} & Sand $(\mathrm{g})$ & 1500 & 1490 & 1480 & 1470 & 1460 & 1450 \\
\hline & Cement (g) & 1000 & 1000 & 1000 & 1000 & 1000 & 1000 \\
\hline & Aggregate $3 / 8(\mathrm{~g})$ & 1500 & 1490 & 1480 & 1470 & 1460 & 1450 \\
\hline & Water $(\mathrm{g})$ & 700 & 700 & 700 & 700 & 700 & 700 \\
\hline \multirow{4}{*}{$\begin{array}{c}\text { Concrete } \\
2\end{array}$} & Sand $(\mathrm{g})$ & 2020 & 2020 & 2009.8 & 1999.6 & 1989.7 & 1979.6 \\
\hline & Cement (g) & 606 & 606 & 606 & 606 & 606 & 606 \\
\hline & Aggregate $3 / 8(\mathrm{~g})$ & 1010 & 1010 & 1010 & 1010 & 1010 & 1010 \\
\hline & Water $(\mathrm{g})$ & 700 & 700 & 700 & 700 & 700 & 700 \\
\hline
\end{tabular}

small variation in the thermophysical properties of the formulation is observed, we have $\lambda=1.0236 \mathrm{~W} /(\mathrm{m} \cdot \mathrm{K}), a=5.309 \times 10^{-7} \mathrm{~m}^{2} \cdot \mathrm{s}^{-1}$ and $\rho \mathrm{c}=1.783 \times 10^{6}$ $\mathrm{J} \cdot \mathrm{m}^{-3} \cdot \mathrm{K}^{-1}$.

When we added more thypha, one increases the amplitude of variation of the properties. When we reach $2.5 \%$ mass of typha one have: $\lambda=0.524 \mathrm{~W} /(\mathrm{m} \cdot \mathrm{K}), a=$ $2.58 \times 10^{-7} \mathrm{~m}^{2} \cdot \mathrm{s}^{-1}$ and $\rho c=1.03 \times 10^{6} \mathrm{~J} \cdot \mathrm{m}^{-3} \cdot \mathrm{K}^{-1}$. This shows the influence of typha on cementitious materials. Figure 5 below shows the evolution of the thermal conductivity of concrete formulation 1 as a function of the percentage of typha by mass.

A second formulation called Concrete 2 was made with a $40 \%$ reduction in the 
binder (cement) and tested to monitor the impact of the cementitious binder on the properties of the material. The samples tested show a marked decrease in the thermal conductivity of the materials as typha is added to the formulations and the amount of binder is reduced. The thermal properties of concrete 2 vary from $\lambda=1.019 \mathrm{~W} /(\mathrm{m} \cdot \mathrm{K}), a=5.239 \times 10^{-7} \mathrm{~m}^{2} \cdot \mathrm{s}^{-1}$ and $\rho c=1.945 \times 10^{6} \mathrm{~J} \cdot \mathrm{m}^{-3} \cdot \mathrm{K}^{-1}$ for the reference material ( $0 \%$ de typha) to $\lambda=0.5 \mathrm{~W} /(\mathrm{m} . \mathrm{K}), a=2.962 \times 10^{-7} \mathrm{~m}^{2} . \mathrm{s}^{-1}$ and $\rho c=1.588 \times 10^{6} \mathrm{~J} \cdot \mathrm{m}^{-3} \cdot \mathrm{K}^{-1}$ for samples with $2.5 \%$ mass of typha. These results are presented in Table 2 .

Figure 6 below summarizes the evolution of the thermal conductivity of the samples of the concrete 2 formulation as a function of the typha ratio.

Above all, it confirms the tendency of typha aggregates to reduce the thermal conductivity of materials according to their abundance in the sample.

A comparison of the two formulations shows the influence of the binder on the thermophysical properties of the samples.

This shows that the addition of typha in cementitious materials reduces their thermal conductivity and thus reinforces their insulating power. Exposed to the sun, this typha concrete will constitute a thermal filter against solar radiation and its use will reduce heat exchange (see Figure 7).

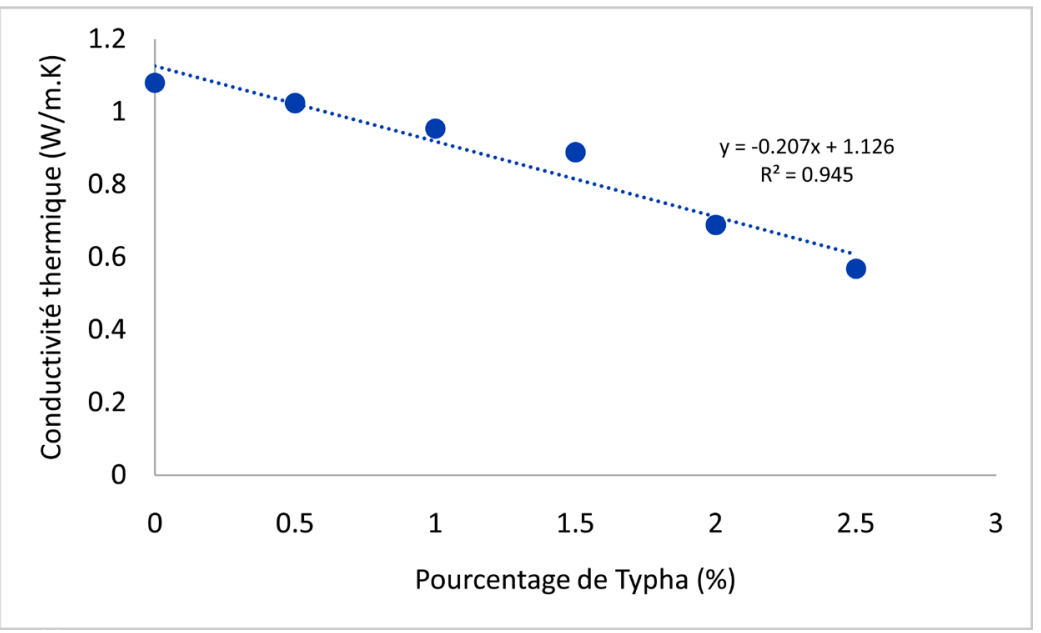

Figure 5. Variation of the thermal conductivity of concrete 1 as a function of the percentage of typha.

Table 2. Thermophisical properties of concrete $1 \& 2$.

\begin{tabular}{lccccccc}
\hline \multirow{2}{*}{ Concretes } & \multirow{2}{*}{ Properties } & \multicolumn{6}{c}{ Mass pourcentage of Typha (\%) } \\
\cline { 3 - 8 } & & 0 & 0.5 & 1 & 1.5 & 2 & 2.5 \\
\hline \multirow{2}{*}{ Concrete 1 } & $\lambda(\mathrm{W} / \mathrm{m} \cdot \mathrm{K})$ & 1.079 & 1.023 & 0.953 & 0.82 & 0.688 & 0.524 \\
& $\mathrm{E}$ & 1407.1 & 1404.83 & 1265.64 & 1117.63 & 111094 & 1031.7 \\
& $\mathrm{a}\left(10^{-7} \mathrm{~m}^{2} \cdot \mathrm{s}^{-1}\right)$ & 5.885 & 5.309 & 5.167 & 4.393 & 3.838 & 2.581 \\
\hline \multirow{2}{*}{ Concrete 2 } & $\lambda(\mathrm{W} / \mathrm{m} \cdot \mathrm{K})$ & 1.019 & 0.99 & 0.911 & 0.888 & 0.646 & 0.501 \\
& $\mathrm{E}$ & 1408.32 & 1406.07 & 1336.85 & 1187.77 & 1056.38 & 1042.937 \\
& $\mathrm{a}\left(10^{-7} \mathrm{~m}^{2} \cdot \mathrm{s}^{-1}\right)$ & 5.238 & 4.962 & 4.647 & 4.19 & 3.74 & 2.36 \\
\hline
\end{tabular}




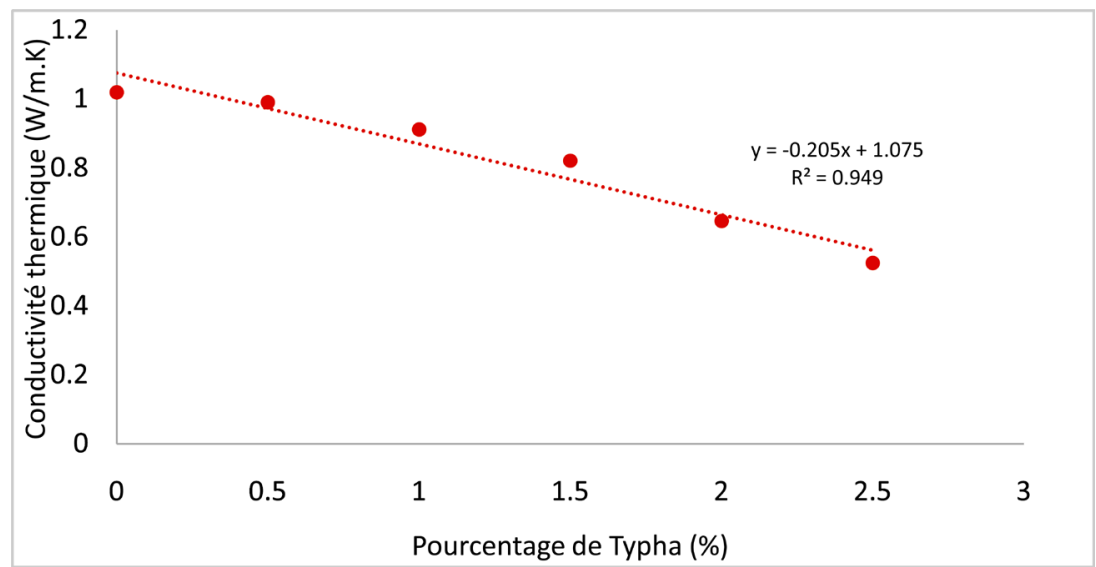

Figure 6. Variation of the thermal conductivity of concrete 2 as a function of the percentage of typha.

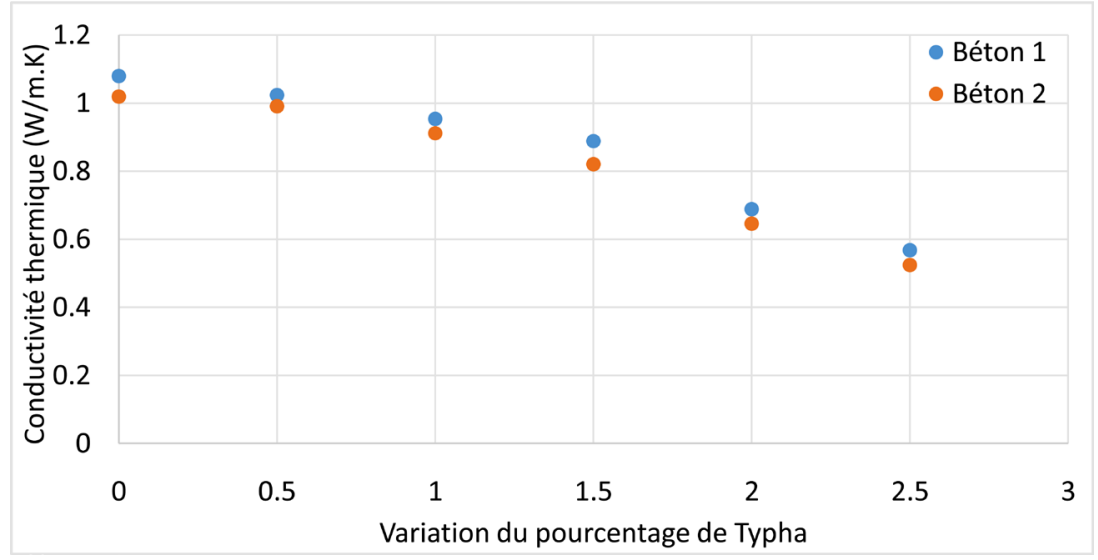

Figure 7. Conparison of concrete $1 \& 2$.

\section{Conclusions and Recommendations}

This study made it possible to highlight the influence of typha aggregates on the thermomechanical properties of building materials but also the impact of the quantity of cement on thermal conductivity. An addition of $2.5 \%$ by mass of Typha makes it possible to divide the thermal conductivity by two, while a reduction in the quantity of cement by $40 \%$ only lowers the thermal conductivity by about 5\%. It shows that the addition of Typha makes possible to produce concretes whose thermal conductivity can reach $\lambda=0.5 \mathrm{~W} /(\mathrm{m} \cdot \mathrm{K})$.

With sufficient mechanical strength for use in infill, typha concrete has proven its performance in reducing the spread of heat and insulation by ricochet in the building.

In perspective, it would be interesting to set up a numerical model capable to predict and simulate the behavior of typha-based materials. Lightweight aggregate concretes offer an alternative compared to conventional materials which are sometimes very expensive and less suitable for construction in tropical areas.

In addition, a study of the evolution of the volume heat capacity of the material for a given typha content as a function of the water content in order to ve- 
rify the linearity between these two parameters is under processing.

\section{Acknowledgements}

National Project on Typha of Senegal (PNEEB/Typha) for granting us a scholarship and for making available to the LME laboratory the Deltalab EI700 thermophysical characterization device and the data acquisition module inside the test building of the LaSTEE laboratory.

\section{Conflicts of Interest}

The authors declare no conflicts of interest regarding the publication of this paper.

\section{References}

[1] Cerema (2020) Pôle réseaux de chaleur-CEREMA. 01 Janvier 2014. [En ligne]. http://www.cerema.fr

[2] MEFP_2018_ODD (2018) Forum politique de haut niveau: objectifs de développement durable. Ministère de l'économie, des finances et du plan du Sénégal, Dakar.

[3] PNEEB/Typha (2014) Capitalisation des résultats de recherches et expériences sur le typha. Programme national de réduction des émissions de GES à travers l'Efficacité Energétique dans le secteur du Bâtiment: Projet de production de matériaux d'isolation thermique à base de Typha, Dakar.

[4] Bal, H., Jannot, Y., Quenette, N., Chenu, A. and Gaye, S. (2012) Water Content Dependence of the Porosity, Density and Thermal Capacity of Laterite Based Bricks with Millet Waste Additive. Construction and Building Materials, 31, 144-150. https://doi.org/10.1016/j.conbuildmat.2011.12.063

[5] Mahamat, A.D., Khayal, M.Y., Thiam, M., Menguy, G. and Gaye, S. (2016) Thermo-Physical Characterization of Clay Bricks Mixed with Agricultural Waste: Case Millet's Pod. International Journal of Emerging Technology and Advanced Engineering, 6, 38-43.

[6] Dieye, Y., Sambou, V., Faye, M., Thiam, A., Adj, M. and Azilinon, D. (2017) Thermo-Mechanical Characterization of a Building Material Based on Typha Australis. Journal of Building Engineering, 9, 142-146. https://doi.org/10.1016/j.jobe.2016.12.007

[7] Diaw, A.S., Sow, D., Ndiaye, M.B., Abdelakh, A.O., Wade, M. and Gaye, S. (2016) Valorization of Typha Australis by its Integration in Building Construction Materials. International Journal of Emerging Technology and Advanced Engineering, 6, 34-37.

[8] Niang, I., et al. (2019) Hygric Behaviour of a Clay-Typha Bio-Based Material for Building. EENVIRO 2018 - Sustainable Solutions for Energy and Environment, 85, 5. https://doi.org/10.1051/e3sconf/20198508004

[9] Diaw, A.S., Bal, H.M., Wade, M. and Gaye, S. (2018) Use Typha Australis in the Habitat for the Improvement of Energy Efficiency of Buildings. Journal of Scientific and Engineering Research, 5, 164-171.

[10] Batsale, J.C., Maillet, D. and Degiovanni, A. (1994) Extension de la méthode des quadripôles thermiques à l'aide de transformations intégrales-calcul du transfert thermique au travers d'un défaut plan bidimensionnel. International Journal of Heat and Mass Transfer, 37, 111-127. 
https://doi.org/10.1016/0017-9310(94)90166-X

[11] Degiovanni, A. (1988) Conduction dans un "mur" multicouche avec sources: extension de la notion de quadripôle. International Journal of Heat and Mass Transfer, 31, 553-557. https://doi.org/10.1016/0017-9310(88)90036-1

[12] Bal, H., Jannot, Y., Demeurie, F. and Gaye, S. (2013) Measurement and Modelisation of the Thermal Conductivity of a Wet Composite Porous Medium: Laterite Based Bricks with Millet Waste Additive. Construction and Building Materials, 41, 586-593.

https://doi.org/10.1016/j.conbuildmat.2012.12.032

[13] De Hoog, F.R. (1982) An Improved Method for Numerical Inversion of Laplace Transforms. Society of Industrial and Applied Mathematics, 3, 357-366. https://doi.org/10.1137/0903022

[14] Jannot, Y. and Meukam, P. (2004) Simplified Estimation Method for the Determination of the Thermal Effusivity and Thermal Conductivity Using a Low Cost Hot Strip. Measurement Science and Technology, 15, 19-32.

https://doi.org/10.1088/0957-0233/15/9/034 